\title{
Breast cancer in male veteran population: an analysis from VA cancer registry
}

\author{
Anita Aggarwal, DO, PhD, ${ }^{1}$ Min-Ling Liu, MD, PhD, ${ }^{2}$ Steven H Krasnow, MD ${ }^{1}$ \\ ${ }^{1}$ Department of Oncology/Hematology, ${ }^{2}$ Pathology and Laboratory Medicine Service, Veterans Affairs Medical Center, \\ Washington DC
}

\begin{abstract}
Background Male breast cancer is rare and makes up < 1\% of all cases of breast cancers. Treatment and survival stage per stage is mainly based on what is known from female breast cancer.

Objectives We determined the pathological features, stage, treatment of breast cancer in male veterans and their survival outcome.

Methods Medical records of male patients diagnosed with breast cancer at the Veterans Affairs Medical Centers of Washington DC, Baltimore, Maryland, and Martinsburg, West Virginia, from 1992-2012 were reviewed after ilnstitutional review board approval.

Results From 1995-2012, 51 male patients with breast cancer were identified from cancer registry. Of those, 57\% were African American, $41 \%$ white, and $2 \%$ other race. Median age was 68 years (range, 44-86 years). Palpable mass was presenting symptoms in $80 \%$, and gynecomastia or bloody nipple discharge in $16 \%$. Family history of breast cancer in immediate family was positive in 11 patients without mention of BRCA genes except in one who was BRCA2-positve. ER/PR (estrogen-/progesterone-receptor) was positive in 71\%, ER-positive/PR-negative in 2\%, ER-positive/PR-positive /HER2-positive in 4\%, ER-negative/PR-negative /HER2-triple negative in 4\%. In all, $41 \%$ and $57 \%$ had right and left breast cancer, respectively; $80 \%$ had mastectomy, $36 \%$ had lymph node involvement (1-13 LN), 90\% had invasive ductal carcinoma, $8 \%$ DCIS, and $2 \%$ sarcoma. Cancer in $26 \%$ was stage I, $38 \%$ stage II, $18 \%$ stage III and $8 \%$ stage IV. Twenty four percent of the patients had combination chemotherapy, and $66 \%$ were given tamoxifen. Eight percent had relapsed or recurrent disease within 1-5 years of their diagnosis and died within $2-12$ years after the relapse. At median follow-up of 174 months (range, 4 months- 19 years), $56 \%$ had died, $42 \%$ were alive, and $6 \%$ had been lost to follow-up.

Limitations This is a very small retrospective chart review. Further large prospective studies are desired.

Conclusions Median age at diagnosis of breast cancer seems to be higher in men (70 years) than it is in women (60 years). Invasive ductal carcinoma is the main pathology, and $73 \%$ of the tumors were ER-positive. The survival rate at more than 10 years of follow-up was about $40 \%$. Stage versus survival revealed no difference in mortality.
\end{abstract}

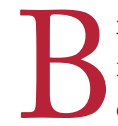
reast cancer in men is a rare disease and makes up less than $1 \%$ of all cases of breast cancer. ${ }^{1-4}$ The rarity of this entity precludes prospective randomized trials. During 2014, about 2,360 new cases of invasive breast cancer will be diagnosed in men and about 430 men will die from the disease. ${ }^{2}$ For men, the lifetime risk of being diagnosed with breast cancer is about 1 in 1,000. Men of any age may develop breast cancer, although it is usually detected in men between 60 and 70 years of age. Radiation exposure, high levels of estrogen, and a family history of breast cancer can increase a man's risk of developing breast cancer. ${ }^{1,5}$ The literature shows that the male breast cancer pathology is similar to that of female breast cancer, and infiltrating ductal cancer is the most common tumor type of male breast cancer. ${ }^{2-4}$ Treatment and survival for men with breast cancer is similar to that of women with breast cancer stage per stage. ${ }^{5-7}$ The impression that male breast cancer has a worse prognosis may stem from the tendency toward diagnosis at a later stage. ${ }^{7-9}$ We determined the risk factors, pathological features, stage and treatment of breast cancer in male veterans and their survival outcome.

\section{Patients and methods}

We performed a retrospective review of medical records of male patients who were diagnosed with breast cancer at the Veterans Affairs Medical Centers (VAMC) in Washington DC, Baltimore, Maryland, and Martinsburg, West Virginia, from 1992-2012, after we obtained approval from VAMC-DC institutional review board. Cases were identified using the VA Central Tumor registry data base. The following data were recorded for each patient: race, age at the time of diagnosis of breast cancer, family history of cancer, chemical/radiation exposure history if available, stage and grade of the cancer,

Accepted for publication March 27, 2014. Correspondence: Anita Aggarwal, DO, PhD; anita.aggarwal@va.gov. Disclosures: The authors have no disclosures. JCSO 2014;12:293-297. (2014 Frontline Medical Communications. DOI $10.12788 /$ icso.0066 


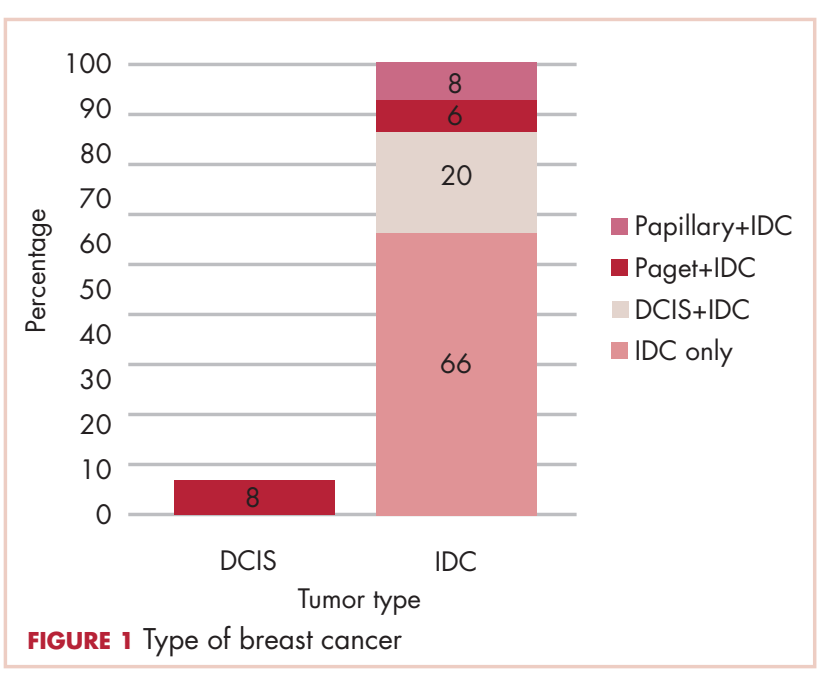

estrogen/progesterone/HER2 (ER/PR/HER2) status, treatments of the breast cancer (surgical, radiation, chemotherapy, hormonal therapy), recurrent disease and survival outcome. Tumor stage is determined using the American Joint Committee on Cancer classification system (AJCC 7), which considers tumor size, nodal involvement, and distant metastases.

\section{Results}

\section{Demographic data}

From 1992-2012, a total of 51 male patients with breast cancer were identified at the 3 VAMCs. Two patients were lost to follow-up or had incomplete records. Of the 51 patients, 29 (57\%) were African American, 21 (41\%) were white, and $1(2 \%)$ was of other race (Table 1). Median age at the time of diagnosis for all patients was 68 years (range, 44-86 years), 70 years for African American patients and 68 years for white patients. The presenting symptom in 41 patients $(80 \%)$ was noted to be a palpable mass. Gynecomastia or bloody nipple discharge in 8 patients (16\%) led to the breast biopsy. Pain was not the presenting symptom in most patients. A history of breast cancer in immediate family (mother and/or sister) was noted in 11 patients without mention of BRCA genes except 1 patient (\#24) who was BRCA2-positive. Data on chemical/radiation exposure was inadequate. As per available data, 3 patients had been exposed to Agent Orange.

\section{Surgical treatment and staging}

In all, $41 \%$ and $59 \%$ patients had right and left breast cancer, respectively. Two patients (4\%) declined surgical intervention. Forty patients $(78 \%)$ had total mastectomy with axillary lymph node dissection, 2 (4\%) had sentinel lymph node biopsy without complete axillary dissection, and 6 (12\%) had no axillary manipulation but had mastectomy only. Eighteen $(36 \%)$ of the patients were found to have lymph node involvement (1-13 LN). In 2 patients (4\%), surgical staging had incomplete documents. Cancer in $26 \%$ of the patients was stage I, $38 \%$ stage II, $18 \%$ stage III, and $8 \%$ stage IV.

\section{Tumor specifications}

Ductal carcinoma in situ (DCIS) was noted in $8 \%$ of the patients, and $92 \%$ had invasive ductal carcinoma (IDC). None had invasive lobular carcinoma or in situ. In patients with IDC, DCIS was seen in 20\%, Paget in 6\%, and papillary in $8 \%$ of IDC cases (Figure 1). Tumor grade in 12\% was not recorded. Grade 1, 2, and 3 was noted in 12\%, 41\%, and $36 \%$, respectively, of the remaining cases.

$\mathrm{ER} / \mathrm{PR}$ was positive in 36 patients (72\%), ER-positive/ PR-negative in 1 (2\%), ER-positive/PR-positive/HER2positive in 2 patients (4\%), and ER-negative/PR-negative/ HER2-triple negative (TN) in $2(4 \%)$ patients. One of the 2 TN patients had DCIS. Hormonal receptor (HR) status was not available in 11 patients (22\%); most of these patients were diagnosed with breast cancer before implementation of CPRS - the Computerized Patient Record System, the VA e-medical records (1998).

\section{Treatment}

In terms of adjuvant treatment, 12 patients (24\%) were treated with combination chemotherapy. Some of them had sequential radiation and/or endocrine therapy after chemotherapy. Endocrine therapy was given to 33 patients (66\%); tamoxifen was the drug of choice in 30 (91\%). Two patients $(6 \%)$ and $1(3 \%)$ had anastrazole and letrozol, respectively; from medical records, it was not clear why these patients received aromatase inhibitors. Sixteen patients (32\%) received local radiation to the breast and axillary area.

\section{Outcome}

As of January 2013 (follow-up period, 14 months-20 years), 28 patients (56\%) died, 21 (42\%) were alive, and 2 (4\%) failed to follow up. Of those who died, $60 \%$ were African American and 40\% were white (Figure 2). Three of the 4 patients who presented with stage IV died within a year of diagnosis; 1 is alive at 8 years of diagnosis. None of the patients had family history of breast cancer. Four patients (8\%) had relapsed/recurrent disease within 1-5 years of their diagnosis. All 4 relapsed patients died in 2-12 years after relapse. Further analysis of stage compared with survival revealed no difference with stage and mortality.

\section{Discussion}

The study confirms that the male veterans present with breast cancer at a later age and most had HR-positive invasive ductal carcinoma. A higher number of male veterans have early-stage breast at presentation. From the 1940s until the 1980s, the incidence of all breast cancer in the 
TABLE 1 Demographics and tumor characteristics of male veteran patients with breast cancer

\section{Characteristic}

No. of

Median age (range), 68 (44-86)

years

Race

African American

29 (57)

White

$21(41)$

Other

$1(2)$

Laterality

$\begin{array}{ll}\text { Right } & 21(41) \\ \text { Left } & 30(59)\end{array}$

Tumor type

DCIS

$4(8)$

Invasive ductal

47 (92)

IDC with Paget

$3(6)$

IDC with papillary

$4(8)$

IDC with DCIS

$10(20)$

Grade

$\begin{array}{cc}1 & 6(12) \\ 2 & 21(41) \\ 3 & 18(36) \\ \text { Unknown } & 6(12)\end{array}$

Stage

Tis

$4(8)$

I

$13(26)$

II

$19(36)$

9 (18)

IV

4 (8)

Unknown

2 (4)

DCIS, ductal carcinoma in situ; IDC, invasive ductal carcinoma; Tis, carcinoma in situ

United States increased because of screening mammography. The Surveillance, Epidemiology, and End Results (SEER) reported 26\% increase in male breast cancer from 1973-1978. After leveling off during the 1990s, the incidence of all breast cancer declined in the early $2000 \mathrm{~s}^{9,10}$ because of a drop in use of hormone replacement therapy that occurred after the Women's Health Initiative study. ${ }^{9-12}$ However, breast cancer is striking relatively young military women and men at alarming rates. ${ }^{13}$

Unpublished data from Walter Reed Army Medical Center in Bethesda, Maryland, found in 2009 that breast cancer rates in military women are "significantly higher" military women are $20 \%-40 \%$ more likely to get the dis-

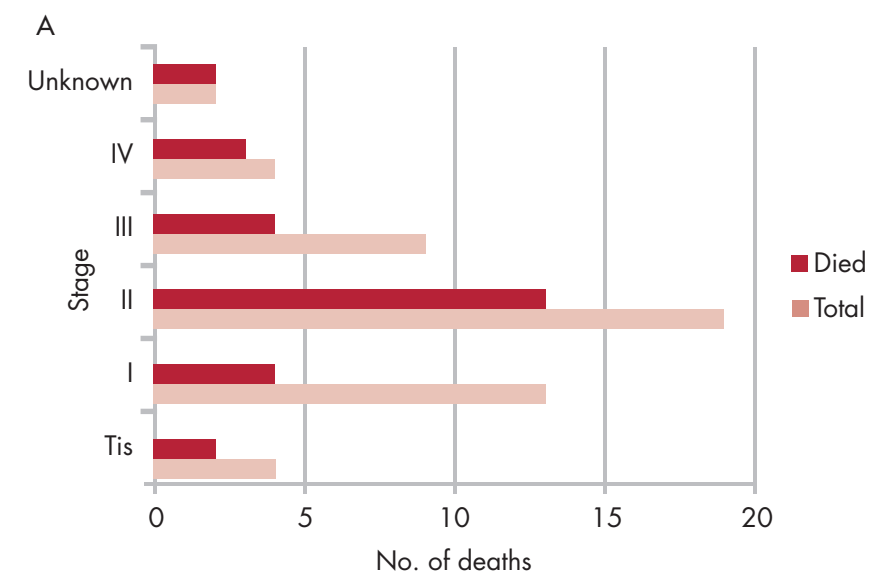

B

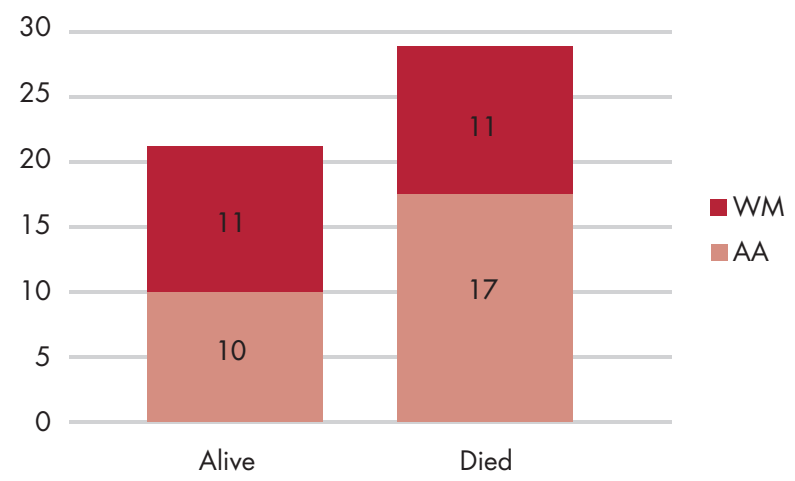

FIGURE 2 Mortality by stage (A) and ethnicity (B)

ease than other nonmilitary women in the same age groups. The etiology of this increased risk is not clear but could be related to chemical and radiation exposure and the use of oral contraceptive in women.

The mean age at diagnosis for male breast cancer in the general population varies among different studies between 62 and 71 years, which is about $5-10$ years older than the average age at diagnosis for women. ${ }^{1}$ The age frequency distribution in women among the general population is bimodal with peaks at 52 and 71 years, whereas in men it is unimodal with a peak age 71 years. ${ }^{14}$ Female veterans seemed to be comparatively younger than the general population of women at the time of diagnosis: 56 years in female veterans, compared with 61 years in the general population. ${ }^{15}$ Nahleh and colleagues ${ }^{16}$ reported that the age at the time of breast cancer diagnosis in male veterans was 67 years, compared with 57 years for female veterans. Our study confirms a median age of 68 years at diagnosis in male veterans. These studies suggest that breast cancer in both male and female veterans is diagnosed earlier than it is in the general population.

Most men with breast cancer have no identifiable risk 
factors. However, several risk factors have been identified similar to female breast cancer such as genetic changes, estrogen excess, liver disease, chest wall radiation, obesity, alcohol abuse, and some occupational and environmental exposure (including but not limited to heat, exhaust emission, and electromagnetic field radiation)..$^{18-22}$ Most of our patients are from the Vietnam or Korean War era. They could have had environmental and/or occupational exposure. Unfortunately, these data were limited in our retrospective study and requires further study.

The most common presenting symptoms in male breast cancer patients are a painless subareolar lump, nipple retraction, and bleeding from the nipple. ${ }^{6}$ Most of our patients presented with palpable mass. Usually, the primary consideration in the differential diagnosis is gynecomastia, which affects about $30 \%$ of healthy men. The diagnostic evaluation and staging system used for male breast cancer are the same as for women. Mammography can be helpful in differentiating gynecomastia from malignant breast disease. The sensitivity and specificity of mammography for the diagnosis of male breast cancer have been reported to be $92 \%$ and $90 \%$, respectively. ${ }^{23}$ As with women, there is a slight preponderance of left-sided versus right-sided disease. $^{24}$

Compared with women, men tend to be diagnosed with later-stage disease, whereas $64 \%$ of the male patients in our sample had early stage (I and II) disease. A recent study by Landrum and colleagues ${ }^{25}$ reported better survival rate in older patients with cancers in the Veterans Health Administration, reportedly from high-quality care, particularly preventive care. Although preventive care was not addressed in that study, it could account for earlier-stage breast cancer at diagnosis in our male veterans compared with the general population.

Male breast tissue is rudimentary. It does not usually differentiate and undergo lobule formation so most of the male breast cancer is ductal carcinoma. For invasive carcinomas, the ranges of histologic subtypes for female and male breast cancer are similar; however, the relative distributions differ. ${ }^{1}$ Data from more than 2,000 male patients in SEER cancer registry show that $93.7 \%$ of male breast cancers are ductal or unclassified carcinomas, $2.6 \%$ are papillary, $1.8 \%$ are mucinous, and $1.5 \%$ are lobular. Ductal carcinoma in situ comprises about $10 \%$ of breast cancers in men. ${ }^{24,26}$ Consistent with published data, our study found that most male veterans had IDC, and that $8 \%$ had DCIS.

Male breast cancers are significantly more likely than are cancers of the female breast to express HR, even after adjustment for tumor stage, grade, and patient age. More than $90 \%$ of male breast cancers express ER/PR ${ }^{1,27,28}$ in contrast to female breast cancers; $60 \%-70 \%$ of female breast cancers are ER- or PR-positive. In our study, $20 \%$ of patients did not have any documentation of HR status but were treated with tamoxifen. Presuming they were ER-/ PR-positive, our data of HR status in male veterans with breast cancer (> 90\%) are consistent with published literature, and $<5 \%$ of our male veterans with breast cancer had HER2 overexpression. The HER2 proto-oncogene is less likely to be overexpressed in cancers of the male breast. ${ }^{29-31}$

Recent studies that used standardized methodology have shown a lower rate of HER2 overexpression in men (2\%-15\%) in comparison with female breast cancers (1820\%). ${ }^{29-31}$ Early reports had suggested equivalent rates of HER-2 overexpression between male and female breast cancers. ${ }^{31-33}$ However, those studies were performed before improved standardization of methodology and probably overestimated HER2-neu overexpression. A recent series of 75 patients found that only $5 \%$ of male breast cancers overexpressed HER2. ${ }^{30}$ Similarly, Bloom and colleagues ${ }^{29}$ found that only 1 of 58 male breast cancers overexpressed HER2, and that none of 58 had gene amplification. The role of the androgen receptor in male breast cancer is unclear and this receptor has not been associated with breast cancer prognosis. ${ }^{34}$

Adjuvant treatment of male breast cancer is same as in females stage per stage. Given the high prevalence of HR-positive disease, tamoxifen remains the gold standard of adjuvant hormonal therapies. Data on the use of aromatase inhibitors in treating male breast cancer are scarce. Future studies with a focus on disease biology are crucial to advance the understanding of male breast cancer and to optimize the care of all male patients.

Disease-specific and overall survival rates in male breast cancer in 1,986 male patients in the SEER database are shown to have notably higher disease-specific survival rates than overall survival rates owing to the older average age of this population and deaths from other comorbid illnesses. The SEER database indicated that survival was equivalent in men and women with early-tage breast cancer. In male breast cancer veteran patients with stage III and IV disease, a study by Nahleh and collegues indicated that overall survival was similar between the 2 groups and was generally low (stage III: 2.56 years for male breast cancer vs 5.51 years for female breast cancer; stage IV: 1.47 years for male breast cancer vs 2.22 years for female breast cancer), consistent with the National Cancer Database and SEER data. ${ }^{2}$

Our study reports $56 \%$ mortality; cause of death is unknown, most likely the result of the comorbidities these older patients had. Stage-specific survival is difficult to assess because of low numbers. But patients with stage IV had highest mortality rate. It is not clear whether this was related to advanced-stage disease. As in the case in women, black men with breast cancer have a worse prognosis than do white men. In our study, $60 \%$ of the African American patients died, compared with $40 \%$ of the white patients. It is difficult to draw any conclusions regarding disease-spe- 
cific mortality and survival of our male veterans because of incomplete data.

Our study has the usual limitations of being a retrospective registry assessment, missing data, lacking individuallevel risk factor data, and having a small sample size. In addition, our study included many patients with unknown HR status and we did not have detailed treatment records.

Our results indicate that male veterans with breast cancer tend to be older at the time of diagnosis compared with female patients, but that they are younger than nonveteran men with breast cancer at time of diagnosis. Furthermore, most male breast cancers were IDC and ER-positive tumors. Stage-specific survival was difficult to assess because of low numbers, but mortality was higher in African American patients than it was in white patients. A better understanding of this disease is needed so that new opportunities for therapeutic intervention may be developed.

\section{References}

1. Giordano SH, Cohen DS, Buzdar AU, Perkins G, Hortobagyi GN. Breast carcinoma in men: a population-based study. Cancer. 2004;101:51-57.

2. American Cancer Society. Cancer Facts and Figures 2014. Atlanta, GA: American Cancer Society, 2014. http://www.cancer.org/cancer/ breastcancerinmen/detailedguide/breast-cancer-in-men-key-statistics. Revised January 31, 2014. Accessed June 11, 2014.

3. American Cancer Society. Cancer Facts and Figures 2012. Atlanta, Ga: American Cancer Society, 2012.

4. Burstein HJ, Harris JR, Morrow M. Malignant tumors of the breast. In: DeVita VT Jr, Lawrence TS, Rosenberg SA: Cancer: Principles and Practice of Oncology. 9th ed. Philadelphia, Pa: Lippincott Williams \& Wilkins, 2011, pp 1401-46.

5. Ravandi-Kashani F, Hayes TG. Male breast cancer: a review of the literature. Eur J Cancer. 1998;34:1341-1347.

6. Giordano SH. A review of diagnosis and management of male breast cancer. Oncologist. 2005;10:471-479.

7. Giordano SH, Buzdar AU, Hortobagyi GN. Breast cancer in men. Ann Inntern Med. 2002;137:678-687.

8. Nahleh Z, Girnius S. Male breast cancer: a gender issue. Nat Clin Pract Oncol. 2003;3:428-437.

9. Howlander N, Noone AM, Krapcho M, et al, eds. SEER Cancer Statistics Review, 1975-2009: Fast Stats. Bethesda, MD: National Cancer Institute. http://seer.cancer.gov/csr/1975_2009_pops09/, 2012. Accessed June 10, 2014.

10. Ravdin PM, Cronin KA, Howlander N, et al. The decrease in breastcancer incidence in 2003 in the United States. N Engl J Med. 2007;356:1670-1674.

11. Kerlikowske K, Miglioretti DL, Buist DS, Walker R, Carney PA. National Cancer Institute-Sponsored Breast Cancer Surveillance Consortium. Declines in invasive breast cancer and use of postmenopausal hormone therapy in a screening mammography population. J Natl Cancer Inst. 2007;99:1335-1339.

12. Chlebowski RT, Kuller LH, Prentice RL, et al. Breast cancer after use of estrogen plus progestin in postmenopausal women. $\mathrm{N} \mathrm{Engl} \mathrm{J}$ Med. 2009;360:573-587.

13. Anderson JR. Alarming breast cancer rates among troops. USA Today. October 2, 2012.
14. Anderson WF, Jatoi I, Tse J, Rosenberg PS. Male breast cancer: a population-based comparison with female breast cancer. J Clin Onc. 2010;28:232-239.

15. Thota R, Subbiah S, Tashi T, Aldoss I. Breast cancer in female veteran population: Survival analysis from VA cancer registry. $2010 \mathrm{JCO}$ abst 170 .

16. Nahleh ZA, Srikantiah R, Safa M, Jazieh AR, Muhleman A, Komrokji R. Male breast cancer in veterans affairs population: a comparative analysis. Cancer. 2007;109:1471-1477.

17. Martin AM, Weber BL. Genetic and hormonal risk factors in breast cancer. J Natl Cancer Inst. 2000;92:1126-1135.

18. Palli D, Masala G, Mariani-Constantini R, et al. A gene environment interaction between occupation and BRCA1/BRCA2 mutations in male breast cancer? Eur J Cancer. 2005;40:2472-2479.

19. Hansen J. Elevated risk for male breast cancer after occupational exposure to gasoline and vehicular combustion products. Am J Int Med. 2000;37:349-352.

20. Ron E, Ikeda T, Preston D1, Tokuoka S. Male breast cancer amongst atomic bomb survivors. J Natl Cancer Inst. 2005;97:603-605.

21. Lowell DM, Martineau RG, Luria SB. Carcinoma of male breast following radiation. Cancer 1968;22:581-586. Renee: I think this has been written incorrectly; I found a similar citation in pubmed but not this one.

22. Sasco AJ, Lowenfels AB, Pasker-de Jong P. Review article: epidemiology of male breast cancer. A meta-analysis of published casecontrol studies and discussion of selected aetiological factors. Int J Cancer. 1993;53:538-549.

23. Evans GF, Anthony T, Turnage RH, et al. The diagnostic accuracy of mammography in evaluation of male breast disease. Am J Surg. 2001;181:96-100.

24. Fentiman IS, Fourquet A, Hortobagyi GN. Male breast cancer. Lancet. 2006;367:595-604.

25. Landrum MB, Keating NL, Lamont EB, et al. Survival of older patients with cancer in Veterans Health Administration versus feefor service Medicare. J Clin Oncol. 2012;30:1072-1079.

26. Stalsberg H, Thomas DB, Rosenblatt KA, et al. Histological types and hormone receptors in breast cancer in men: a population based study in 282 United States men. Cancer Causes Control. 1993;4:143-151.

27. Dawson PJ, Paine TM, Wolman SR. Immunocytochemical characterization of male breast cancer. Mod Pathol. 1992;5:621-625.

28. Wick MR, Sayadi H, Ritter JH, Hill DA, Reddy VB, Gattuso P. Low-stage carcinoma of the male breast. A histologic, immunohistochemical, and flow cytometric comparison with localized female breast carcinoma. Am J Clin Pathol. 1999;111:59-69.

29. Bloom KJ, Govil H, Gattuso P, Reddy V, Francescatti D. Status of HER-2 in male and female breast carcinoma. Am J Surg. 2001;182:389-392.

30. Muir D, Kanthan R, Kanthan SC. Male versus female breast cancers. A population-based comparative immunohistochemical analysis. Arch Pathol Lab Med. 2003;127:36-41.

31. Blin N, Kardas I, Welter C, et al. Expression of the c-erbB2 protooncogene in male breast carcinoma: lack of prognostic significance. Oncology. 1993;50:408-411.

32. Leach IH, Ellis IO, Elston CW. c-erb-B-2 expression in male breast carcinoma. J Clin Pathol. 1992;45:942.

33. Rayson D, Erlichman C, Suman VJ, et al. Molecular markers in male breast carcinoma. Cancer. 1998;83:1947-1955.

34. Pich A, Margaria E, Chiusa L, et al. Androgen receptor expression in male breast carcinoma: lack of clinicopathological association. Br J Cancer. 1999;79:959-964. 